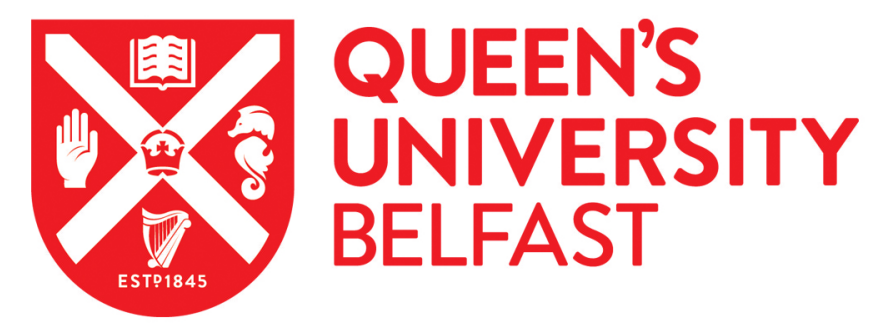

\title{
Ethylene Response Factor (ERF) genes modulate plant root exudate composition and the attraction of plant parasitic nematodes
}

Dyer, S., Weir, R., Cox, D., Cheseto, X., Torto, B., \& Dalzell, J. J. (2019). Ethylene Response Factor (ERF) genes modulate plant root exudate composition and the attraction of plant parasitic nematodes. International Journal for Parasitology, 49(13-14), 999-1003. https://doi.org/10.1016/j.ijpara.2019.09.001

Published in:

International Journal for Parasitology

Document Version:

Peer reviewed version

Queen's University Belfast - Research Portal:

Link to publication record in Queen's University Belfast Research Portal

\section{Publisher rights}

(c) 2019 Australian Society for Parasitology. Published by Elsevier Ltd. All rights reserved.

This manuscript is distributed under a Creative Commons Attribution-NonCommercial-NoDerivs License

(https://creativecommons.org/licenses/by-nc-nd/4.0/), which permits distribution and reproduction for non-commercial purposes, provided the author and source are cited.

\section{General rights}

Copyright for the publications made accessible via the Queen's University Belfast Research Portal is retained by the author(s) and / or other copyright owners and it is a condition of accessing these publications that users recognise and abide by the legal requirements associated with these rights.

\section{Take down policy}

The Research Portal is Queen's institutional repository that provides access to Queen's research output. Every effort has been made to ensure that content in the Research Portal does not infringe any person's rights, or applicable UK laws. If you discover content in the

Research Portal that you believe breaches copyright or violates any law, please contact openaccess@qub.ac.uk. 
2 Ethylene Response Factor (ERF) genes modulate plant

3 root exudate composition and the attraction of plant

4 parasitic nematodes

5

6 Steven Dyer ${ }^{a}$, Ryan Weir ${ }^{a}$, Deborah Cox ${ }^{a}$, Xavier Cheseto ${ }^{b}$, Baldwyn Torto ${ }^{b}$, Johnathan J.

7 Dalzella,*

8

9 a School of Biological Sciences, Queen's University Belfast, Northern Ireland

${ }^{\mathrm{b}}$ The International Center of Insect Physiology and Ecology (ICIPE), Nairobi, Kenya

11

12

*Corresponding author: j.dalzell@qub.ac.uk

13 


\section{Abstract}

17 Plant root exudates are compositionally diverse, plastic and adaptive. Ethylene signalling 18 influences the attraction of plant parasitic nematodes (PPNs), presumably through the modulation of root exudate composition. Understanding this pathway could lead to new sources of crop parasite resistance. Here we used Virus-Induced Gene Silencing (VIGS) to knock down the expression of two Ethylene Response Factor (ERF) genes, ERF-E2 and ERFE3, in tomato. Root exudates were significantly more attractive to the PPNs Meloidogyne incognita and Globodera pallida following knockdown of ERF-E2, which had no impact on the attraction of Meloidogyne javanica. Knockdown of ERF-E3 had no impact on the attraction of Meloidogyne or Globodera spp. Gas Chromatography Mass Spectrometry (GCMS) analysis revealed major changes in root exudate composition relative to controls. However, these changes did not alter the attraction of rhizosphere microbes Bacillus subtilis or Agrobacterium tumefaciens. This study further supports the potential of engineering plant root exudate for parasite control, through the modulation of plant genes. subtilis; Agrobacterium tumefaciens; VIGS; Host finding; Tomato 
Plant parasitic nematodes (PPNs) are estimated to reduce crop yield by $12.3 \%-25 \%$ globally each year (Coyne et al., 2018; Nicol et al., 2011). The non-feeding second stage PPN juvenile (J2) hatches in the soil, and must find and invade a suitable host plant by following concentration gradients of water-soluble and volatile components of plant root exudate (Čepulytè et al., 2018; Murungi et al., 2018). We previously demonstrated that the modulation of $A B C$ transporter genes and sugar transporter genes can alter plant root exudate composition, and parasite hatching and attraction ex planta (Cox et al., 2019a; Warnock et al., 2016). This represents an interesting approach to crop plant resistance, as it manipulates parasite behaviour in the rhizosphere, and limits host invasion events that can lead to secondary infection, and metabolically expensive defence responses. However, our capacity to engineer beneficial root exudate profiles is limited by a lack of fundamental insight into the complex genotype-environment-phenotype interaction that underpins this biology.

Ethylene is a gaseous plant hormone that plays a key role in regulating growth, development and physiological response to stress (Ju and Chang, 2015). Ethylene receptors are localised to the endoplasmic reticulum, and constitutively inhibit downstream signalling pathways through the action of a Ser/Thr kinase called Constitutive Triple Response 1 (CTR1). Ethylene receptor agonism interferes with receptor-mediated activation of CTR1, leading to the transcriptional activation of Ethylene Response Factor (ERF) genes. ERF proteins belong to the APETALA2/ERF transcription factor family, and regulate ethyleneresponsive genes through binding to GCC-box elements (Mizoi et al., 2012). Ethylene is linked to various aspects of host-PPN interactions (Wubben et al., 2001, 2004; Piya et al., 2019; Warmerdam et al., 2019), and Inhibition of ethylene signalling enhances attraction of the root knot nematode Meloidogyne hapla, and the cyst nematode Heterodera glycines, to plant roots (Fudali et al., 2013; Hu et al., 2017). This indicates that constitutive receptormediated activation of CTR1 and negative regulation of ERF genes in the absence of ethylene, promotes attraction of PPNs. We therefore hypothesise that one or more ERF genes must regulate root exudate composition and parasite attraction. On that basis, knockdown of implicated ERF genes should phenocopy the elevated attraction of PPNs to root exudates, as observed when host plants are treated with ethylene synthesis inhibitors. Such genes could be exploited as novel sources of resistance through gain of function mutation, or over-expression. 
ERF-E2 and ERF-E3 are expressed constitutively in tomato plants; however, the expression of ERF-E2 increases during fruit development and ripening, whereas ERF-E3 expression decreases (Liu et al., 2016). PPN species synchronise their life-cycle with that of host plants. For example, potato cyst nematodes hatch at a very low frequency without the positive stimulus of host plant root exudate, and they respond differently to root exudates that have been collected from developmentally distinct host plants (Byrne et al., 2001). We further hypothesised that ERF genes which are activated towards the end of the host lifecycle (e.g. during fruiting - ERF-E2) are more likely to mediate root exudate changes that repel PPNs, which may represent an adaptive response of the PPN to ensure selection of a host with long-term viability. Here we used Virus Induced Gene Silencing (VIGS) to investigate the role of ERF-E2 and ERF-E3 genes in regulating root exudate composition, and PPN attraction to tomato $\mathrm{cv}$. Moneymaker.

The experimental workflow and approach is similar to that of Cox et al. (2019a). Two hundred bp regions of ERF-E2 and ERF-E3 were synthesised individually, with a shared contiguous 200 bp region of the visual reporter gene, PDS. These DNA segments were incorporated into the binary VIGS vector, pTRV2, yielding pTRV2-ERF-E2:PDS, and pTRV2ERF-E3:PDS, which were used in this study, together with pTRV2-PDS and pTRV1. PTRV1 and the pTRV2 variants were transformed into Agrobacterium tumefaciens strain LB4404, individually by electroporation. Tomato seedlings were inoculated by topical application of mixed pTRV1 and pTRV2 cultures (one of pTRV2-ERF-E2:PDS, pTRV2-ERF-E3:PDS, or pTRV2PDS for each experimental mixture), following the methodology of Cox et al. (2019a). All downstream assays were conducted using root exudates collected from the timepoint with the highest level of gene knockdown, equating to week 3 post-inoculation for ERF-E2, and week 4 post-inoculation in the case of ERF-E3 (Fig. 1). In both cases, the gene transcript level was reduced $>50 \%$ relative to controls (ERF-E2 $(0.42 \pm 0.04, P<0.001)$ and ERF-E3 $(0.39 \pm 0.01$, $P<0.001))$. Sequence alignment revealed that $E R F-E 2$ and $E R F-E 3$ shared the highest levels of non-target sequence similarity with each other, and served as off-target specificity controls for the VIGS process. Although non-target ERF gene expression was slightly reduced in both cases, differences were not statistically significant relative to controls (Fig. 1).

Root exudate was collected from plants following VIGS, and was used to assess the impact of gene knockdown on parasite attraction (Figs. 1 and 2A). Despite Meloidogyne incognita and Meloidogyne javanica being closely related, our data indicate a striking 
variation in responses to root exudates collected following ERF-E2 knockdown; $M$. incognita displayed enhanced attraction relative to controls, whereas $M$. javanica did not. We have observed similar variation between Meloidogyne spp. in response to exudates collected after $A B C$ transport gene knockdown (Cox et al., 2019a). For this line of research to develop robust and durable new sources of PPN resistance, it will be important to establish the behavioural impacts that such interventions have on geographically coincident species, as well as different populations of a given species (Cox et al., 2019b). Nonetheless, our data indicate that ERF-E2 knockdown phenocopies the enhanced attraction of certain PPN species, which is also observed following the inhibition of ethylene signalling (Fudali et al., 2013; Hu et al., 2017). It is possible that other ERF genes contribute to this interaction (positively or negatively), which necessitates further investigation.

We also sought to investigate the impact that ERF gene knockdown had on the attraction of economically relevant rhizosphere microbes to collected root exudates (Fig. 1B and C). Active chemotaxis is important for initial colonisation of plant roots by the Plant Growth-Promoting Rhizobacterium (PGPR) Bacillus subtilis (Allard-Massicotte et al., 2016), and the crown gall pathogen, Agrobacterium tumefaciens (Merritt et al., 2007). Our data indicate that the attraction of $B$. subtilis and $A$. tumefaciens is not altered relative to PDS controls. This suggests that it may be possible to develop novel sources of crop parasite resistance, through the manipulation of root exudate composition, without affecting other important plant-rhizosphere interactions.

The GC-MS dataset indicates significant compositional changes in root exudates following knockdown of ERF-E2 or ERF-E3 (in addition to PDS), relative to control root exudates (PDS knockdown only). However, it is important to note that our analysis does not encompass the full spectrum of root exudate chemistry. Although we have demonstrated that octadecanoic acid is an inhibitor of PPN attraction in previous work (Cox et al., 2019a), our data suggest that it is not a biologically relevant inhibitor following ERF-E2 knockdown, despite being significantly elevated, together with 2,3-dimethylpropyl octadecanoate (Fig. 3). This suggests that other compositional changes have a greater influence on PPN behaviour in this context; similar observations have been documented previously (Kihika et al., 2017). Additional investigation will be required to determine whether the enhanced attraction of M. incognita and G. pallida to exudates collected following ERF-E2 knockdown is a result of increased attractant(s), or decreased repellent(s). The GC-MS data also 
demonstrate a substantial developmental influence on exudate composition, with control exudates exhibiting clear differences between week 3 and week 4 post-inoculation. This agrees with previous work on the link between developmental stage and root exudate composition (Chaparro et al., 2013). Collectively, our data suggest that ERF gene knockdown may have widespread impacts on transcriptional networks and metabolic pathways contributing to exudate composition. Further work will be required to identify genes that are regulated by ERF-E2 (and other ERF proteins), which would allow more specific and targeted interventions for exudate modification and parasite resistance.

Our data indicate that $M$. incognita and G. pallida regulate their behaviour ex planta in response to $E R F-E 2$, but not ERF-E3. This corroborates our hypothesis that one or more $E R F$ gene products regulate root exudate composition, phenocopying the enhanced attraction of PPNs observed following the inhibition of ethylene synthesis (Fudali et al., 2013; Hu et al., 2017). Our data also demonstrate that M. incognita and G. pallida use developmentally regulated signalling processes in the host plant to coordinate host selection behaviour ex planta. ERF-E2 expression increases during host fruiting, whereas ERF-E3 expression decreases (Liu et al., 2016). Meloidogyne javanica does not, however, respond in the same way as the other species, which warrants further investigation. Collectively, our data point to the potential application of $E R F$ genes, or genes that are regulated by ERF transcription factors, in the manipulation of parasite behaviour in the rhizosphere. It may be possible to enhance the efficacy of trap crops, or push-pull strategies, through breeding or biotechnology that exploits this line of research. Encouragingly, we did not observe any impact on the behaviour of non-target soil microbes, suggesting that parasite-specific interventions may be possible. Considerable progress has been made in developing novel sources of resistance to the parasitic plant, Striga spp., through the manipulation of root exudate composition (; Jamil et al., 2011; Samejima et al., 2016; Gobena et al., 2017). Whilst there is still much unknown about how PPNs perceive and respond to plant root exudates, recent work continues to provide valuable insight into their ex planta biology and behaviour (Warnock et al., 2016; Čepulytė et al., 2018; Hoysted et al., 2018; Kirwa et al., 2018; Bell et al., 2019; Cox et al., 2019a, 2019b; Tsai et al., 2019; ).

\section{Acknowledgements}



pilot grant, both from the Department for the Economy, Northern Ireland.

\section{References}

Allard-Massicotte, R., Tessier, L., Lecuyer, F., Lakshmanan, V., Lucier, J.F., Garneau, D., Caudwell, L., Vlamakis, H., Bais, H.P., Beauregard, P.B., 2016. Bacillus subtilis early colonization of Arabidopsis thaliana roots involves multiple chemotaxis receptors. MBio 7(6): e01664-16. http://doi.org/10.1128/mBio.01664-16

Bell, C.A., Lilley, C.J., McCarthy, J., Atkinson, H.J., Urwin, P.E., 2019. Plant-parasitic nematodes respond to root exudate signals with host-specific gene expression patterns. PLoS Pathog. 15(2): e1007503. https://doi.org/10.1371/journal.ppat.1007503

Byren, J.T., Maher, N.J., Jones, P.W., 2001. Comparative responses of Globodera rostochiensis and G. pallida to hatching chemicals. J Nematol. 33(4): 195-202. PMID: 19265881

Čepulytè, R., Danquah, W.B., Bruening, G., Williamson, V.M., 2018. Potent Attractant for Root-Knot Nematodes in Exudates from Seedling Root Tips of Two Host Species. Sci Rep 8: 10847 https://doi.org/10.1038/s41598-018-29165-4

Chaparro, J.M., Badri, D.V., Bakker, M.G., Sugiyama, A., Manter, D.K., Vivanco, J.M., 2013. Root Exudation of Phytochemicals in Arabidopsis Follows Specific Patterns That Are Developmentally Programmed and Correlate with Soil Microbial Functions. PLoS ONE 8(2): e55731. https://doi.org/10.1371/journal.pone.0055731

Coyne, D.L., Cortada, L., Dalzell, J.J., Claudius-Cole, A.O., Haukeland, S., Luambano, N., Talwana, H., 2018. Plant-parasitic nematodes and food security in sub-Saharan Africa. Annu. Rev. Phytopathol. 56: 381-403. https://doi.org/10.1146/annurevphyto-080417-045833

Cox, D., Dyer, S., Weir, R., Cheseto, X., Sturrock, M., Coyne, D., Torto, B., Maule, A.G., Dalzell, J.J., 2019a. ABC transporters alter plant-microbe-parasite interactions in the rhizosphere. BioRxiv https://doi.org/10.1101/526582

Cox, D., Reilly, B., Warnock, N.D., Dyer, S., Sturrock, M., Cortada, L., Coyne, D., Maule, A.G., Dalzell, J.J., 2019b. Transcriptional signatures of invasiveness in Meloidogyne incognita populations from sub-Saharan Africa. Int J Parasitol. 49, 837-841 
Fudali, S.L., Wang, C., Williamson, V.M., 2013. Ethylene signalling pathway modulates attractiveness of host roots to the root-knot nematode Meloidogyne hapla. Mol Plant Microbe Interact. 26(1): 75-86. https://doi.org/10.1094/MPMI-05-12-0107-R

Gobena, D., Shimels, M., Rich, P.J., Ruyter-Spira, C., Bouwmeester, H., Kanuganti, S., Mengiste, T., Ejeta, G., 2017. Mutation in sorghum LOW GERMINATION STIMULANT 1 alters strigolactones and causes Striga resistance. PNAS 114(17): 4471-4476. http://doi.org/10.1073/pnas.1618965114

Hu, Y., You, J., Li, C., Williamson, V.M., Wang, C., 2017. Ethylene response pathway modulates attractiveness of plant roots to soybean cyst nematode Heterodera glycines. Sci Rep. 7: 41282. https://doi.org/10.1038/srep41282

Jamil, M., Charnikhova, T., Houshyani, B., van Ast, A., Bouwmeester, H.J., 2012. Genetic variation in strigolactone production and tillering in rice and its effect on Striga hermonthica infection. Planta 235(3): 473-484. http://doi.org/10.1007/s00425-011$\underline{1520-y}$

Ju, C., Chang, C., 2015. Mechanistic insights in ethylene perception and signal transduction Plant Physiology 169(1): 85-95 https://doi.org/10.1104/pp.15.00845

Kihika, R., Murungi, L.K., Coyne, D., Ng'ang'a, M., Hassanali, A., Teal, P.E.A., Torto, B., 2017. Parasitic nematode Meloidogyne incognita interactions with different Capsicum annum cultivars reveal the chemical constituents modulating root herbivory. Sci Rep 7: 2903. https://doi.org/10.1038/s41598-017-02379-8

Kirwa, H.K., Murungi, L.K., Beck, J.J., Torto, B., 2018. Elicitation of Differential Responses in the Root-Knot Nematode Meloidogyne incognita to Tomato Root Exudate Cytokinin, Flavonoids, and Alkaloids. J Agric Food Chem 66(43): 11291-11300. https://doi.org/10.1021/acs.jafc.8b05101

Liu, M., Gomes B.L., Mila, I., Purgatto, E., Peres, L.E.P., Frasse, P., Maza, E., Zouine, M., Roustan, J-P., Bouzayen, M., Pirrello, J., 2016. Comprehensive profiling of ethylene response factor expression identifies ripening-associated $E R F$ genes and their link to key regulators of fruit ripening in tomato. Plant Physiol. 170(3): 1732-1744. https://doi.org/10.1104/pp.15.01859

Merritt, P.M., Danhorn, T., Fuqua, C, 2007. Motility and chemotaxis in Agrobacterium tumefaciens surface attachment and biofilm formation. J Bacteriol. 189(22): 80058014. https://doi.org/10.1128/JB.00566-07 
Mizoi, J., Shinozaki, K., Yamaguchi-Shinozaki, K., 2012. AP2/ERF family transcription factors in plant abiotic stress responses. Biochim Biophys Acta 1819: 86-96.

\section{https://doi.org/10.1016/j.bbagrm.2011.08.004}

Murungi, L.K., Kirwa, H., Coyne, D., Teal, P.E.A., Beck, J.J., Torto, B., 2018. Identification of key root volatiles signaling preference of tomato over spinach by the root knot nematode Meloidogyne incognita. J Agric Food Chem 66: 7328-7336. https://doi.org/10.1021/acs.jafc.8b03257

Nicol, J.M., Stirling, G.R., Turner, S.J., Coyne, D.L., de Nijs, L., Hockland, S., Maafi, Z.T., 2011. Current nematode threats to world agriculture. In: Jones JT, Gheysen G, Fenoll C., (eds), Genomics and Molecular Genetics of Plant-Nematode Interactions. Springer, Heidelberg pp. 21-44. https://doi.org/10.1007/978-94-007-0434-3 2

Piya, S., Binder, B.M., Hewezi, T,. 2019. Canonical and noncanonical ethylene signalling pathways that regulate Arabidopsis susceptibility to the cyst nematode Heterodera schachtii. New Phytol. 221(2): 946-959. https://doi.org/10.1111/nph.15400

Samejima, H., Babiker, A.G., Mustafa, A., Sugimoto, Y,. 2016. Identification of Striga hermonthica-resistant upland rice varieties in Sudan and their resistant phenotypes. Front Plant Sci. 7: 634. https://doi.org/10.3389/fpls.2016.00634

Tsai, A.Y., Higaki, T., Nguyen, C.N., Perfus-Barbeoch, L., Favery, B., Sawa, S., 2019. Regulation of root-knot nematode behaviour by seed-coat mucilage-derived attractants. Mol Plant. 12(1): 99-112. https://doi.org/10.1016/j.molp.2018.11.008

Warmerdam, S., Sterken, M.G., Van Schaik, C., Oortwijn, M.E.P., Lozano-Torres, J.L., Bakker, J., Goverse, A., Smant, G., 2019. Meidator of tolerance to abiotic stress ERF6 regulates susceptibility of Arabidopsis to Meloidogyne incognita. Mol Plant Pathol 20(1): 137-152. https://doi.org/10.1111/mpp.12745

Warnock, N.D., Wilson, L., Canet-Perez, J.V., Fleming, T., Fleming, C.C., Maule, A.G., Dalzell, J.J., 2016. Exogenous RNA interference exposes contrasting roles for sugar exudation in host-finding by plant pathogens. Int J Parasitol 46, 473-7. https://doi.org/10.1016/i.ijpara.2016.02.005

Wubben, M.J., Rodermel, S.R., Baum, T.J., 2004. Mutation of a UDP-glucose-4-epimerase alters nematode susceptibility and ethylene responses in Arabidopsis roots. Plant J. 40(5): 712-724. https://doi.org/10.1111/j.1365-313X.2004.02257.x 
Wubben, M.J., Su, H., Rodermel, S.R., Baum, T.J., 2001. Susceptibility to the sugar beet cyst nematode is modulated by ethylene signal transduction in Arabidopsis thaliana. Mol Plant Microbe Interact. 14(10): 1206-12.

\section{https://doi.org/10.1094/MPMI.2001.14.10.1206}

\section{Figures}
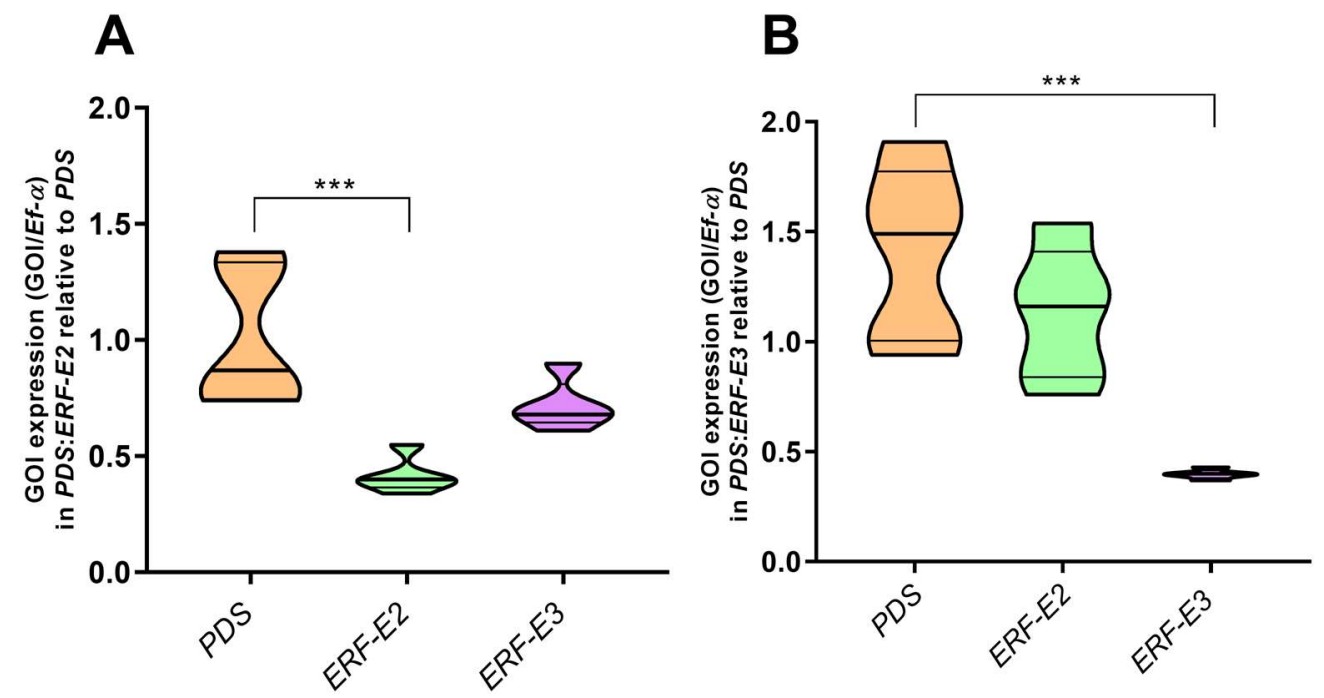

Gene of interest expression

Fig. 1. Virus Induced Gene Silencing (VIGS) reduces the expression level of target ETHYLENE RESPONSE FACTOR (ERF) genes. Violin plots indicate median (inner emboldened line) and quartile (outer lines) expression values for control (PHYTOENE DESATURASE [PDS] only) and experimental groups (ERF-E2 and ERF-E3). (A) Target ERF-E2 expression is significantly reduced relative to the control, whereas the most similar non-target gene, ERF-E3, was not significantly reduced. (B) Target ERF-E3 expression is significantly reduced relative to the control, whereas the most similar non-target gene, ERF-E2, was not significantly reduced. Three VIGS-responsive plants (exhibiting leaf photobleaching following PDS knockdown) were pooled to produce one biological replicate, with six biological replicates used per target gene. Root tissue was gently washed free of soil, and snap frozen in liquid nitrogen. Frozen tissue was then homogenised in a pestle and mortar. Total RNA was extracted using the Maxwell ${ }^{\circledR} 16$ LEV Plant RNA Kit and automated Maxwell ${ }^{\circledR} 16$ AS2000 Instrument. DNA was removed using the Turbo DNase free kit (Life Technologies UK) according to the 
manufacturer's instructions. RNA was quantified by measuring the absorbance at $260 \mathrm{~nm}$. All samples were normalised to $1000 \mathrm{ng}$ of RNA using nuclease free $\mathrm{H}_{2} \mathrm{O}$. cDNA was synthesised using the High-capacity RNA-to-cDNA kit (Applied Biosciences, UK) and diluted five-fold prior to amplification with nuclease free $\mathrm{H}_{2} \mathrm{O}$. Transcript abundance was assessed two, three, four and 6 weeks post-inoculation by Reverse Transcription (RT) - quantitative (q)PCR. RT-qPCR was performed in triplicate for each cDNA sample using a Rotorgene $Q$

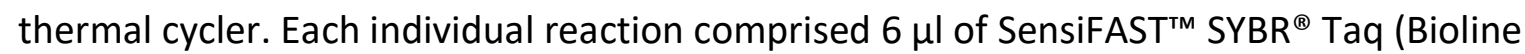
UK), $0.8 \mu \mathrm{l}$ of forward and reverse primers (EF- $\alpha$ [Solyc06g005060] F: TACTGGTGGTTTTGAAGCTG, R: AACTTCCTTCACGATTTCATCATA; PDS [Solyc03g123760] F: GAAGGCGCTGTCTTATCAGG, R: GCTTGCTTCCGACAACTTCT; ERF-E2 [Solyc06g063070] F: GAAGTTCTTGCAGATCCCATATC, R: GTACATCATCGAAGGACCAAAG; ERF-E3 [Solyc03g123500] F: GGCAAGAAGGCTAAGGTAAAC, R: CTCCACGCTGTTCATGATTG), $2.4 \mu$ of nuclease-free $\mathrm{H}_{2} \mathrm{O}$ and $2 \mu \mathrm{l}$ of cDNA. The conditions for the reactions were as follows: $95^{\circ} \mathrm{C} \times 10 \mathrm{~min}, 45 \times\left(95^{\circ} \mathrm{C}\right.$ $\left.\times 10 \mathrm{~s}, 60^{\circ} \mathrm{C} \times 20 \mathrm{~s}, 72^{\circ} \mathrm{C} \times 25^{\circ} \mathrm{C}\right), 67^{\circ} \mathrm{C}->95^{\circ} \mathrm{C}$ rising in $1^{\circ} \mathrm{C}$ increments. PCR efficiencies for all reactions were calculated using Rotorgene $Q$ software. Relative quantification of target transcript was calculated using the ${ }^{\Delta \Delta} \mathrm{Ct}$ method relative to the endogenous housekeeping gene, elongation factor 1 alpha $(E F-\alpha)$. Knockdown of each target gene was calculated as a ratio of expression relative to PDS knockdown (using pTRV2-PDS) in control plants. All data were assessed by one-way ANOVA and Tukey's multiple comparison test using Graphpad Prism 8. ${ }^{* * *} P<0.001$. 

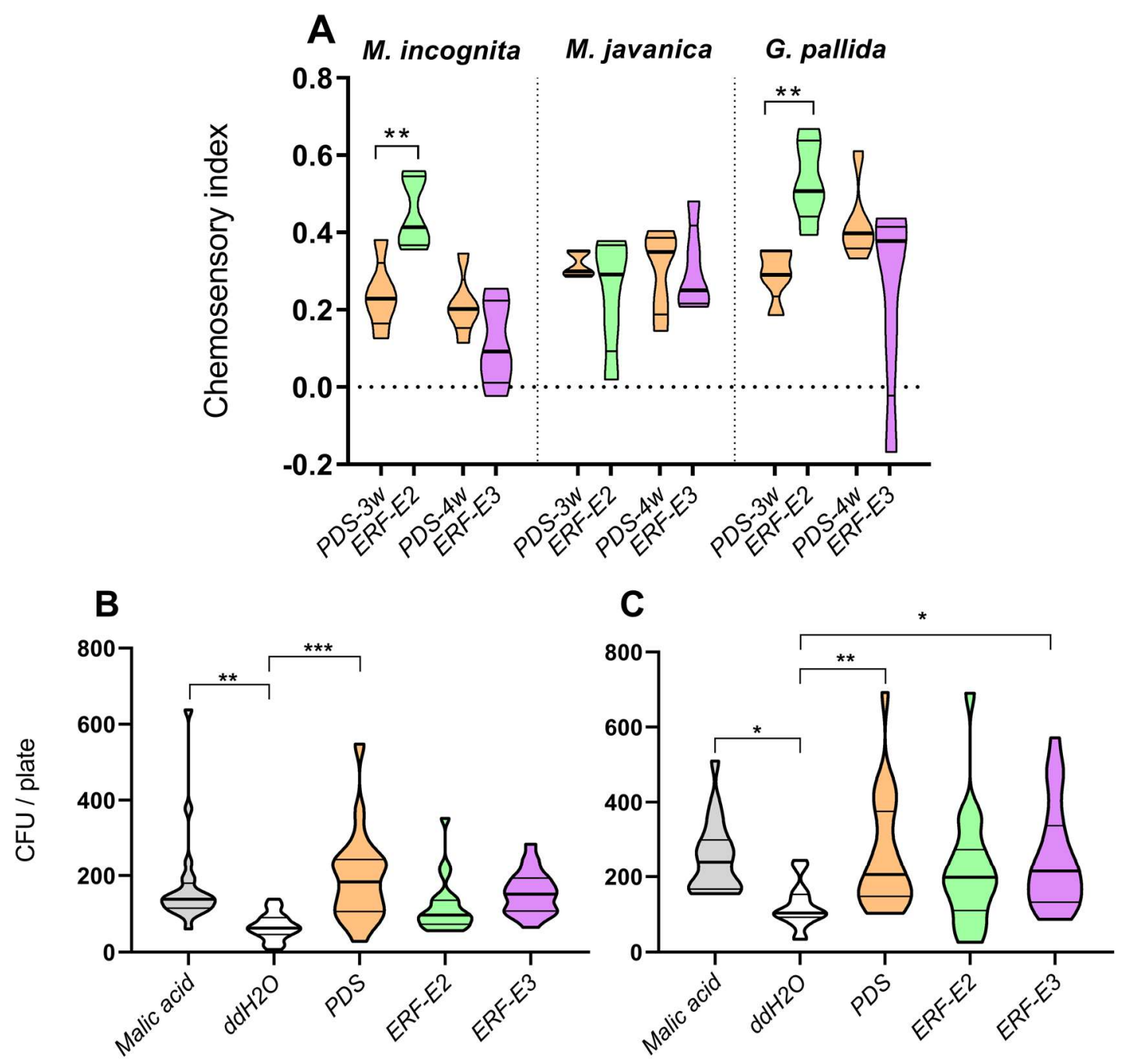

Experimental group

Fig. 2. ETHYLENE RESPONSE FACTOR (ERF) gene knockdown modifies parasite attraction to tomato root exudate. Violin plots indicate median (inner emboldened line) and quartile (outer lines) values. (A) Knockdown of ERF-E2 enhances the attraction of Meloidogyne incognita and Globodera pallida, but not Meloidogyne javanica. Plant Parasitic Nematode (PPN) maintenance, handling and experimentation was conducted as in Cox et al. (2019a). Briefly, Meloidogyne spp. were cultured in tomato cv. Moneymaker, which were maintained in a Panasonic MLR-352 plant growth cabinet ( $16: 8 \mathrm{~h}$ light:dark, $23^{\circ} \mathrm{C}$, Photosynthetic Photon Flux Density [PPFD] $\left.50 \mu \mathrm{mol} \cdot \mathrm{m}-2 \cdot \mathrm{s}^{-1}\right)$. Eggs were hatched in sterile spring water, and used immediately for chemosensory assays. Globodera pallida was maintained on potato cv. Kerr's Pink under field conditions in Belfast, Northern Ireland. Cysts were incubated in tomato root exudate diluted $1: 1$ with double distilled (dd) $\mathrm{H}_{2} \mathrm{O}$, and freshly 
hatched J2s were taken immediately for chemosensory assays. Root exudates were collected from plants following gene knockdown, by submerging the root tips in $10 \mathrm{ml}$ of $\mathrm{dd}_{2} \mathrm{O}$ for $24 \mathrm{~h}$ in growth chambers. The plants were removed, and the $\mathrm{ddH}_{2} \mathrm{O} /$ root exudate solution was passed through a $0.22 \mu \mathrm{m}$ filter by syringe and stored at $4{ }^{\circ} \mathrm{C}$ until use. All chemosensory assays were conducted in $60 \mathrm{~mm}$ Petri dishes with a $3 \mathrm{ml}$ base of solidified $1.5 \%$ water agar and a surface layer of $3 \mathrm{ml}$ of $0.5 \%$ agar slurry, as in Cox et al. (2019a). Autoclaved Whatman filter paper No. 1 discs ( $5 \mathrm{~mm}$ diameter) were saturated in $20 \mu \mathrm{l}$ of sterile root exudate solutions, or $\mathrm{dd}_{2} \mathrm{O}$, and were placed at each end of the Petri dish immediately prior to pipetting 150 freshly hatched PPN J2s in the centre. The assays were maintained at room temperature in the dark to allow the nematodes to migrate. After $16 \mathrm{~h}$ the number of $\mathrm{J} 2 \mathrm{~s}$ residing in each zone of the assay arena were counted and used to calculate a chemosensory index, as a measure of net attraction / repulsion from the positive root exudate disc. Those in the central dead zone were not counted. $3 w$ refers to three weeks after inoculation; $4 \mathrm{w}$ refers to four weeks after inoculation. (B) Knockdown of ERF genes has no statistically significant impact on the attraction of Agrobacterium tumefaciens or (C) Bacillus subtilis to experimental root exudates. There was no statistically significant difference between attraction of either A. tumefaciens or B. subtilis to exudates collected following ERF-E2 or ERF-E3 knockdown, relative to exudates collected following PDS knockdown ( $P>0.05)$. Microbial chemotaxis assays were conducted as in Cox et al. (2019a) using B. subtilis (168) and $A$. tumefaciens (AGL-1), relative to $\mathrm{dd}_{2} \mathrm{O}$ (negative control), malic acid (positive control, and week 3 PHYTOENE DESATURASE (PDS) exudate (Virus Induced Gene Silencing [VIGS] control). One $\mu$ microcapillary tubes (Sigma-Alrdich UK) were filled with either experimental root exudates (ERF-E2, ERF-E3, or PDS), positive (1 mM malic acid), or negative $\left(\mathrm{ddH}_{2} \mathrm{O}\right)$ controls. The microcapillary tubes were then placed into a microbial cell suspension (within a 96-well plate) for $1 \mathrm{~h}$, and maintained at $23^{\circ} \mathrm{C}$. Following the assay timecourse, the capillary tubes were removed and excess cell suspension was removed from the outside of each capillary tube by rinsing briefly with $d_{d d} \mathrm{H}_{2} \mathrm{O}$. The $1 \mu \mathrm{l}$ content of each capillary tube was ejected into $99 \mu$ of chemotaxis buffer by positive pressure. Twendy $\mu$ of each solution were spread onto a 1.5\% Luria Broth (LB) agar plate. LB plates were sealed with parafilm, and incubated at $28^{\circ} \mathrm{C}$ for $A$. tumefaciens, or $37^{\circ} \mathrm{C}$ for $B$. subtilis, for $48 \mathrm{~h}$. Colony forming units (CFUs) were counted for each replicate plate. All data were assessed 

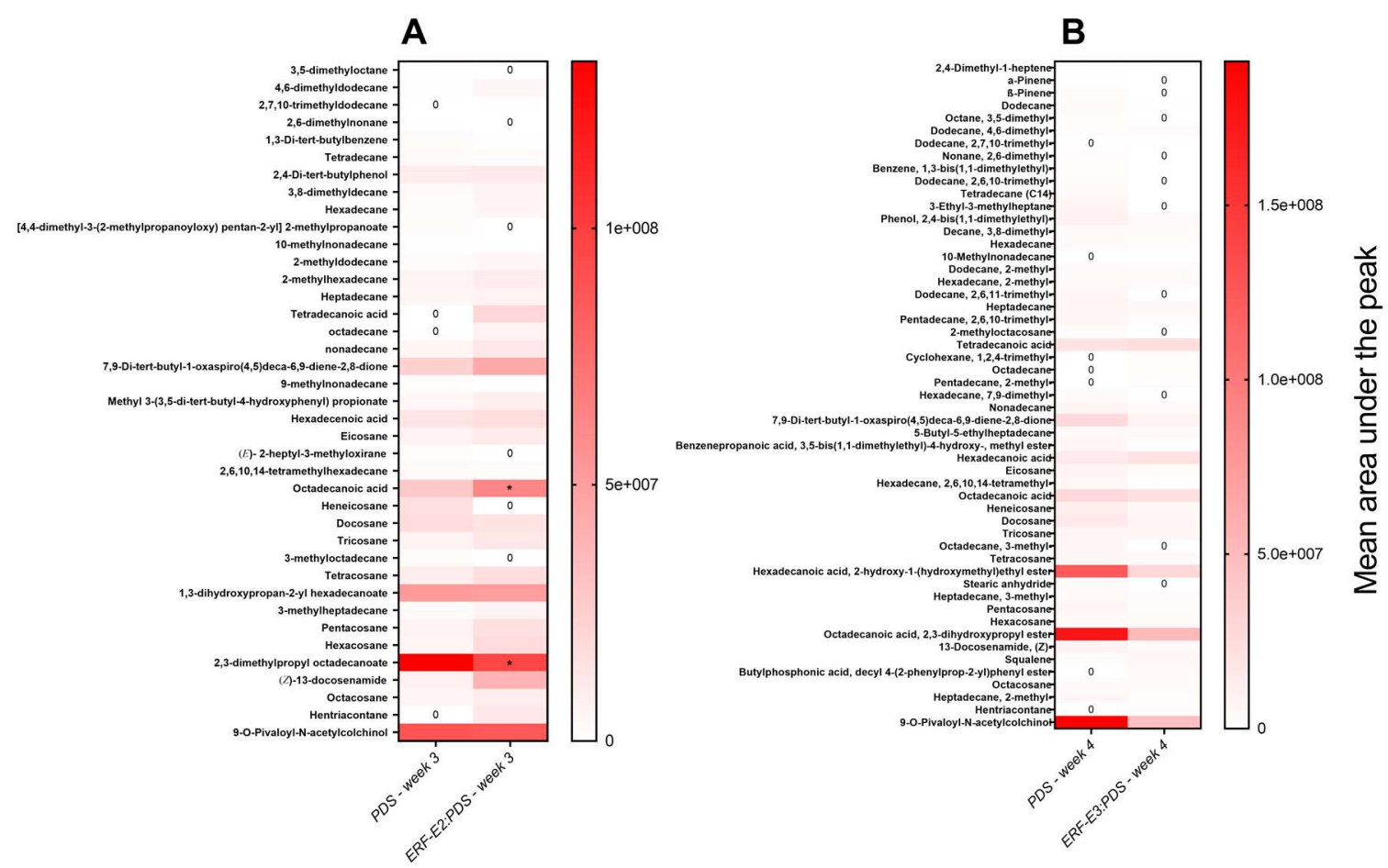

Experimental treatment

Fig. 3. Heatmap showing differences in the relative abundance of identified root exudate compounds across experimental exudates. The mean composition of 10 biological replicates (three plants per replicate) is plotted for each experimental group post-Virus Induced Gene Silencing (VIGS), and has been assessed by two-way ANOVA, and Tukey's multiple comparison test. ' 0 ' indicates that the compound was not detected. Statistical significance is indicated relative to the PHYTOENE DESATURASE (PDS) knockdown control, ${ }^{*} P<0.05$. Root exudates were freeze dried and stored at $-80^{\circ} \mathrm{C}$ until processing (10 biological replicates for each treatment group). Samples were extracted with analytical grade dichloromethane $(1 \mathrm{ml})$

352 (Sigma-Aldrich, USA), vortexed for $10 \mathrm{~s}$, sonicated for $5 \mathrm{~min}$, and centrifuged at 16,000 $\mathrm{g}$ for $5 \mathrm{~min}$. The organic phase was dried over anhydrous $\mathrm{Na}_{2} \mathrm{SO}_{4}$, concentrated to $50 \mu \mathrm{L}$ under a gentle stream of N2 and then analysed $(1.0 \mu \mathrm{l})$ by GC-MS on a 7890A gas chromatograph linked to a 5975 C mass selective detector (Agilent Technologies, USA). The GC was fitted with a HP5 MS low bleed capillary column (30 m × $0.25 \mathrm{~mm}$ inner diameter (i.d.), $0.25 \mu \mathrm{m}$ ) (J\&W, Folsom, CA, USA). Helium at a flow rate of $1.25 \mathrm{ml} \mathrm{min}^{-1}$ served as the carrier gas. The oven temperature was programmed from 35 to $285^{\circ} \mathrm{C}$ with the initial temperature maintained for 
$3595 \mathrm{~min}$, then $10^{\circ} \mathrm{C} \mathrm{min}-1$ to $280^{\circ} \mathrm{C}$ and held at this temperature for $20.4 \mathrm{~min}$. The mass selective 360 detector was maintained at ion source temperature of $230^{\circ} \mathrm{C}$ and a quadrupole temperature 361 of $180^{\circ} \mathrm{C}$. Electron impact (EI) mass spectra were obtained at the acceleration energy of 70 $362 \mathrm{eV}$. Fragment ions were analysed over $40-550 \mathrm{~m} / \mathrm{z}$ mass range in the full scan mode. The 363 filament delay time was set at $3.3 \mathrm{~min}$. A HP Z220 SFF intel xeon workstation equipped with 364 ChemStation B.02.02 acquisition software was used. The mass spectrum was generated for 365 each peak using Chemstation integrator set as follows: initial threshold $=5$, initial peak width $366=0.1$, initial area reject $=1$ and shoulder detection $=$ on. The compounds were identified by 367 comparison of mass spectrometric data and retention times with those of authentic standards 368 and reference spectra published by library-MS databases: National Institute of Standards and 369 Technology (NIST) 05, 08, and 11 